\title{
Pathways to Care in Patients approaching Community Mental Health Satellite Clinics in North India
}

\author{
${ }^{1}$ Shubh M Singh, ${ }^{2}$ Eish Kumar, ${ }^{3}$ Rajoo Saroj, ${ }^{4}$ Ashirbad Satapathy, ${ }^{5}$ Subodh B Nanjayya, ${ }^{6}$ Akhilesh Sharma
}

\begin{abstract}
Introduction: Research into pathway to care (PC) in mental health in India has focussed on severe mental illness in mental hospitals.
\end{abstract}

Aim: To assess PC in a cohort of health care seeking subjects from a predominantly rural background approaching weekly community mental health satellite clinics in three towns in North India.

Materials and methods: 104 consecutive patients over a period of 6 months were included in the study. PC was assessed using a validated instrument.

Results: A majority of the participants were diagnosed with common mental disorders (CMD). The mean duration of symptoms was 22.97 months and the mean number of treatment contacts was 1.11 . Primary care physicians were the most common initial point of contact rather than native/religious healers.

Conclusion: In a CMD predominant treatment seeking population in a rural community where affordable mental health care and primary health care is available, there is high acceptability and utilization of such services.

Clinical significance: Community psychiatry services should ideally be situated alongside primary health care services

Keywords: Community psychiatry, Mental illness, Pathways to care, Public health, Rural psychiatry.

How to cite this article: Singh SM, Kumar E, Saroj R, Satapathy A, Nanjayya SB, Sharma A. Pathways to Care in Patients approaching Community Mental Health Satellite Clinics in North India. J Postgrad Med Edu Res 2018;52(1):12-15.

\section{Source of support: Nil}

Conflict of interest: None

\section{INTRODUCTION}

Pathway to care can be understood as a description of the journey that a patient adopts in seeking health care until she reaches the appropriate health care facility. The PC, in a specific context, is dependent on a host of personal,

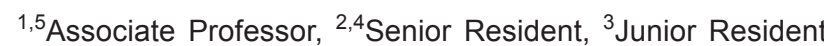
${ }^{6}$ Assistant Professor

${ }^{1-6}$ Department of Psychiatry, Postgraduate Institute of Medical Education \& Research, Chandigarh, India
}

Corresponding Author: Shubh M Singh, Associate Professor, Department of Psychiatry, Postgraduate Institute of Medical Education \& Research, Chandigarh, India, Phone: +91911722756816, e-mail: shubhmohan@gmail.com environmental, economic, and psychosocial factors. ${ }^{1}$ Study of PC can lead to insights into how to make mental health care more accessible to the neglected sections of society. ${ }^{1}$

Research into PC in mental health in India has focused on severe mental disorder (SMD)-predominant populations in mental hospitals. ${ }^{2-6}$ The PC in these populations is likely to be different from that of the vast majority of people that suffer from common mental disorders (CMDs) in the community. ${ }^{7}$ This is because these populations were predominantly suffering from SMD, which have different cultural explanations and help-seeking behaviors and also because these studies were mostly conducted in states, such as Madhya Pradesh and Rajasthan, which stand lower on parameters, such as the human development index (HDI) than Haryana and Punjab in which in this study was conducted. ${ }^{8}$ This is reflected in the results of these studies, wherein most of the patients were suffering from schizophrenia and bipolar disorder, and faith healers were a predominant initial agency of mental health care. ${ }^{2,3,6}$

This study was designed to evaluate PC in a CMDpredominant, treatment-seeking population approaching community mental health satellite clinics (CC) in the states of Haryana and Punjab in North India.

\section{MATERIALS AND METHODS}

The States of Haryana and Punjab are in North India and rank higher in the HDI (ranked 5 and 6 respectively) than the national average of India. ${ }^{9}$ This indicates a higher than national average level of education, per-capita income, and life expectancy, indicative of better health care. This study was conducted in patients attending CC run by the Department of Psychiatry of a tertiary hospital in North India in Raipur Rani and Naraingarh in the state of Haryana and Kharar in Punjab. Raipur Rani is a census town in the district of Panchkula, and Naraingarh is a city in the Ambala district of Haryana. Both of these are surrounded by predominantly rural areas. Raipur Rani has a Community Health Center and Naraingarh is serviced by a Civil Hospital. Kharar is a municipal area in the Sahibzada Ajit Singh Nagar district of Punjab. It is serviced by a civil hospital. In addition, there are private practitioners as well as other informal ones including native/religious healers. People can also be advised to seek treatment at other treatment centers. 
People seeking health care are free to choose whatever health care provider they want to. ${ }^{10}$ The study areas are predominantly rural, but being in geographical proximity to the capital city of Chandigarh has also meant that these areas are undergoing rapid industrialization and more educational opportunities are available. The Department of Psychiatry of a tertiary hospital in this area has been running weekly CCs in each of these health facilities since January 2014. A community mental health team comprising psychiatrists and social workers visits each of these centers. Free medication is provided in Raipur Rani and Naraingarh through the Government of Haryana. Prior to starting of this service, there was no psychiatrist available locally, and people had to travel, if required, to Chandigarh or Ambala or approach local health care providers for their mental health needs.

The study protocol was passed by the Institute's ethics committee. We assessed 104 consecutive patients, who provided written informed consent at these three service facilities over a period of 6 months from March 2016 onward. All participants were $>18$ years of age. Sociodemographic and clinical details were recorded. The PC was assessed using the PC encounter form. ${ }^{7}$ Wherever the participant found difficulty, the investigator could help by explaining the information needed.

\section{RESULTS}

We approached 124 consecutive patients of which 104 agreed to participate in the study. Reasons for refusal to participate in the study were lack of time and inability to remember details needed for completion of the PC encounter form.

Table 1 presents the sociodemographic and geographic details about reasons of delay in seeking treatment and mean number of treatment contacts including index contact. A majority of the patients were from Raipur Rani and Naraingarh CC (84.61\%). Totally, 55 (52.88\%) of the participants were males. About $77.88 \%$ of the participants had at least some education and $73.07 \%$ were from rural areas. The average reported monthly income was Rs. 15,000 (mostly underreported). About $67.30 \%$ participants attributed lack of awareness regarding the psychological nature of symptoms as the reason for delay in approaching the psychiatric services.

A majority of the participants were diagnosed with mild and moderate depressive disorders and anxiety disorders (34.60 and 20.20\% prevalence respectively). This was followed by patients with substance abuse disorders and dissociative disorders (9.6 and 7.7\% respectively). About $7.7 \%{ }^{8}$ participants were diagnosed with schizophrenia.

Table 2 presents the PC of the participants. Government hospital (GH) includes the nonpsychiatrist doctors at the community health center at Raipur Rani and the civil hospitals at Naraingarh and Kharar respectively. A majority of patients who approached community psychiatry service (CP) with $\mathrm{GH}$ as the first PC contact were referred by the latter. Treatment records for a majority of participants were unavailable. However, at the first contact, $16.3 \%$ had received symptomatic treatment, $13.5 \%$ had received antidepressants, and $21.2 \%$ were referred to another treatment setting. The proportion of regular psychotropic-based care increased at each health care encounter.

Participants did not statistically differ from each other on the above parameters with regard to gender or treatment center.

\section{DISCUSSION}

This study represents an investigation of the PC in a mostly rural CP from North India. As is apparent from Table 1 , the study population was characterized by low levels of illiteracy, financial stability, ease of access to affordable health care, and possibility of referral and access to a tertiary care in relative geographic proximity. The sociodemographic profile of the participants was representative of the patient population that approaches the $\mathrm{CC}$ in our experience. The diagnostic breakup indicates a preponderance of depressive and anxiety disorders. Thus, this study adds new information to literature with respect to PC from India, which has mostly focused on SMD patients attending mental hospitals and other tertiary hospitals. ${ }^{2,3,11-13}$ As reported elsewhere, in community

Table 1: Sociodemographic and PC profile

\begin{tabular}{|c|c|c|c|c|c|c|}
\hline $\begin{array}{l}\text { Community } \\
\text { mental health } \\
\text { care facility }\end{array}$ & $\begin{array}{l}N \text { (male + } \\
\text { female) }\end{array}$ & $\begin{array}{l}\text { Mean age in } \\
\text { years }(S D)\end{array}$ & $\begin{array}{l}\text { Illiterate } N \text { (male + } \\
\text { female) }(\%)\end{array}$ & $\begin{array}{l}\text { Within } 40 \mathrm{~km} \text { of } \\
\text { the health facility } \\
n(\%)\end{array}$ & $\begin{array}{l}\text { Mean duration of } \\
\text { symptoms in months } \\
\text { before first treatment } \\
\text { contact }(S D)\end{array}$ & $\begin{array}{l}\text { Mean number of } \\
\text { treatment contacts } \\
\text { prior to present } \\
\text { contact }(S D)\end{array}$ \\
\hline Raipur Rani & $27(9+18)$ & $40.81(18.68)$ & $9(7+2)(33.33)$ & $26(96.29)$ & $17.77(15.81)$ & $1.37(0.88)$ \\
\hline Naraingarh & $61(37+24)$ & $39.45(14.50)$ & $13(8+5)(21.31)$ & $56(91.80)$ & $24.81(37.76)$ & $1.04(0.78)$ \\
\hline Kharar & $16(9+7)$ & $40.92(16.38)$ & $1(0+1)(6.25)$ & $11(68.75)$ & $24.68(46.84)$ & $0.93(0.68)$ \\
\hline
\end{tabular}

SD: Standard deviation 


\begin{tabular}{|c|c|c|c|c|c|c|c|c|}
\hline 1 st contact & $N(\%)$ & $\begin{array}{l}\text { Pathway } \\
N(\%)\end{array}$ & $\begin{array}{l}\text { 2nd contact } \\
N(\%)\end{array}$ & $\begin{array}{l}\text { Pathway } \\
N(\%)\end{array}$ & $\begin{array}{l}\text { 3rd contact } \\
N(\%)\end{array}$ & $\begin{array}{l}\text { Pathway } \\
N(\%)\end{array}$ & 4th contact & $\begin{array}{l}\text { Pathway } \\
N(\%)\end{array}$ \\
\hline $\begin{array}{l}\text { Native/religious } \\
\text { healer }\end{array}$ & $12(11.5)$ & $\begin{array}{l}4 \text { (33.33) PM } \\
1 \text { (8.3) PP } \\
2(16.7) \mathrm{GH} \\
5(41.7) \mathrm{CP}\end{array}$ & & & & & & \\
\hline $\begin{array}{l}\text { Social worker/ } \\
\text { community nurse }\end{array}$ & $6(5.7)$ & $\begin{array}{l}1 \text { (16.66) PM } \\
1(16.66) \mathrm{PP} \\
3(50) \mathrm{GH} \\
1(16.66) \mathrm{CP}\end{array}$ & & & & & & \\
\hline PM & 20 (19.3) & $\begin{array}{l}1(5) \mathrm{PM} \\
5(25) \mathrm{GH} \\
14(70) \mathrm{CP}\end{array}$ & $12(14.45)$ & $\begin{array}{l}3(25) \mathrm{GH} \\
9(75) \mathrm{CP}\end{array}$ & $1(3.3)$ & $1(100) \mathrm{CP}$ & & \\
\hline $\mathrm{GH}$ & $38(36.5)$ & $\begin{array}{l}6(15.78) \mathrm{PM} \\
5(13.15) \mathrm{PP} \\
1(2.63) \mathrm{GH} \\
26(68.42) \mathrm{CP}\end{array}$ & $11(13.26)$ & $\begin{array}{l}1 \text { (9.09) PM } \\
1(9.09) \mathrm{PP} \\
1(9.09) \mathrm{GH} \\
8(72.72) \mathrm{CP}\end{array}$ & 4 (13.3) & $\begin{array}{l}1(25) \mathrm{PP} \\
3(75) \mathrm{CP}\end{array}$ & & \\
\hline PP & $7(6.7)$ & $7(100) \mathrm{CP}$ & 7 (8.43) & $7(100) \mathrm{CP}$ & $1(3.3)$ & $1(100) \mathrm{CP}$ & $1(16.66)$ & $1(100) \mathrm{CP}$ \\
\hline $\mathrm{CP}$ & $21(20.2)$ & & $53(63.85)$ & & $24(80.0)$ & & $5(83.33)$ & \\
\hline Total & 104 & & 83 & & 30 & & 6 & \\
\hline
\end{tabular}

PM: Private medical practitioner; PP: Private psychiatrist

health care settings, there is a preponderance of CMD across genders rather than severe mental illness (SMI). ${ }^{14}$ Thus, the study participants were representative of the patient profile presenting to the CC with regard to sociodemographic parameters, geographical background, and clinical profile.

An analysis of patterns of PC revealed the following differences from results reported elsewhere. The number of PC encounters and duration of symptoms prior to treatment contact was less than has been reported elsewhere, and the most common first treatment encounter was with the GH service providers. This is in contrast to studies that have shown greater number of PC encounters before contact with psychiatrists, a longer duration of symptoms before institution of help-seeking, and a preference for native/religious healers as the first health care contact. ${ }^{2,3,13}$ Most participants also attributed delay in treatment to poor awareness of the psychological nature of the symptoms and approached the $\mathrm{GH}$ or were referred for psychiatric care by the former.

These results indicate that in a CMD-predominant, treatment-seeking population in a rural community where government-based health care and free medication are available, there is high acceptability and utilization of such services. This may be influenced by levels of education and per-capita income as well. This finding is likely to be true for CMD, which generally present with somatic symptoms. Earlier studies have also shown that patients with CMD are more accepting and feel less stigmatized when they feel that there is a medical reason behind their symptoms or when they are referred by a physician to seek medical care. ${ }^{15,16}$ Physician referrals are generally respected because of cultural reasons by which doctors are generally seen as figures of authority and respect. Another implication could also be that the high rates of referral from GH indicate that most physicians can recognize the likelihood of psychiatric disorders and are comfortable referring patients to psychiatric services, if these are available close at hand. It is likely that faith healers and religious/native healers are more prominent in the PC of disorders where the symptoms are more bizarre or disruptive and cannot be attributed to physical illness. Our results suggest that availability of affordable, accessible mental health care in proximity to primary health care facilities is likely to be an important factor in treatment seeking in CMDs.

The limitations of the study include the low prevalence of SMI in the study population, which is known to have a different PC. Secondly, the sample size was small and the study design was cross-sectional. Finally, the setting of the study in the premises of GHs with a preponderance of referrals from primary care physicians may have biased the results.

Future studies should focus on the PC of CMD in areas where health care and psychiatrists are not easily available. There is a need to assess the reasons behind the acceptability of mental health services in a CMDpredominant population and whether the lessons can be extrapolated to patients with SMI.

\section{REFERENCES}

1. Rogler LH, Cortes DE. Help-seeking pathways: a unifying concept in mental health care. Am J Psychiatry 1993 Apr;150(4):554-561.

2. Jain N, Gautam S, Jain S, Gupta ID, Batra L, Sharma R, Singh H. Pathway to psychiatric care in a tertiary mental health facility in Jaipur, India. Asian J Psychiatr 2012 Dec;5(4):303-308. 
3. Lahariya C, Singhal S, Gupta S, Mishra A. Pathway of care among psychiatric patients attending a mental health institution in central India. Indian J Psychiatry 2010Dec;52(4):333-338.

4. Balhara YP, Prakash S, Gupta R. Pathways to care of alcoholdependent patients: an exploratory study from a tertiary care substance use disorder treatment center. Int J High Risk Behav Addict 2016 Sep;5(3):e30342.

5. Pradhan SC, Singh MM, Singh RA, Das J, Ram D, Patil B, Jain AK, Thomas JK. First care givers of mentally ill patients: a multicenter study. Indian J Med Sci 2001 Apr;55(4): 203-208.

6. Chadda RK, Agarwal V, Singh MC, Raheja D. Help seeking behaviour of psychiatric patients before seeking care at a mental hospital. Int J Soc Psychiatry 2001 Winter;47(4): 71-78.

7. Gater R, de Almeida e Sousa B, Barrientos G, Caraveo J, Chandrashekar CR, Dhadphale M, Goldberg D, al Kathiri AH, Mubbashar M, Silhan K, et al. The pathways to psychiatric care: a cross-cultural study. Psychol Med 1991 Aug;21(3): 761-774.

8. Rahi M. Human development report 2010: changes in parameters and perspectives. Indian J Public Health 2011 Oct-Dec;55(4):272-275.

9. Desai, S.; Vanneman, R. India human development survey-II (IHDS-II), 2011-12. Ann Arbor (MI): Inter-university consortium for political and social research; 2015.
10. Chokshi M, Patil B, Khanna R, Neogi SB, Sharma J, Paul VK, Zodpey S. Health systems in India. J Perinatol 2016 Dec;36(Suppl 3):S9-S12.

11. Hashimoto N, Fujisawa D, Giasuddin NA, Kenchaiah BK, Narmandakh A, Dugerragchaa K, Tamrakar SM, Adhikari SR, Sartorius N. Pathways to mental health care in Bangladesh, India, Japan, Mongolia, and Nepal. Asia Pac J Public Health 2015 Mar;27(2):NP1847-NP1857.

12. Prabhu A, Vishnu Vardhan G, Pandit LV. Pathways to tertiary care adopted by individuals with psychiatric illness. Asian J Psychiatr 2015 Aug;16:32-35.

13. Naik SK, Pattanayak S, Gupta CS, Pattanayak RD. Helpseeking behaviors among caregivers of schizophrenia and other psychotic patients: a hospital-based study in two geographically and culturally distinct Indian cities. Indian J Psychol Med 2012 Oct-Dec;34(4):338-345.

14. Kumari S, Mishra SN, Chaudhury S, Singh AR, Verma AN, Kumari S. An experience of community mental health program in rural areas of Jharkhand. Ind Psychiatry J 2009 Jan-Jun;18(1):47-50.

15. Singh SM, Subodh BN, Mehra A, Mehdi A. Reactions to psychiatry referral in patients presenting to medical and surgical outpatient services. Indian J Psychol Med 2017 SepOct;39(5):605-610.

16. Srinivasan K, Isaacs AN, Villanueva E, Lucas A, Raghunath D. Medical attribution of common mental disorders in a rural Indian population. Asian J Psychiatr 2010 Sep;3(3):142-144. 